\title{
Modelling the effect of suspended load transport and tidal asymmetry on the equilibrium tidal sand wave height
}

\author{
W. van Gerwen ${ }^{\text {a,b, }}$, B.W. Borsje ${ }^{\text {a }}$, J.H. Damveld ${ }^{\text {a }}$, S.J.M.H. Hulscher ${ }^{\text {a }}$ \\ ${ }^{a}$ Water Engineering and Management, University of Twente, Enschede, The Netherlands \\ ${ }^{\mathrm{b}}$ Hoogheemraadschap Hollands Noorderkwartier, Heerhugowaard, The Netherlands
}

\section{A R T I C L E I N F O}

\section{Keywords:}

Morphodynamic modelling

Tidal sand waves

Equilibrium height

Delft3D

North Sea

\begin{abstract}
A B S T R A C T
Tidal sand waves are rhythmic bed forms found in shallow sandy coastal seas, reaching heights up to ten meters and migration rates of several meters per year. Because of their dynamic behaviour, unravelling the physical processes behind the growth of these bed forms is of particular interest to science and offshore industries. Various modelling efforts have given a good description of the initial stages of sand wave formation by adopting a linear stability analysis on the coupled system of water movement and the sandy seabed. However, the physical processes causing sand waves to grow towards equilibrium are far from understood. We adopt a numerical shallow water model (Delft3D) to study the growth of sand waves towards a stable equilibrium.

It is shown that both suspended load transport and tidal asymmetry reduce the equilibrium sand wave height. A residual current results in asymmetrical bed forms that migrate in the direction of the residual current. The combination of suspended load transport and tidal asymmetry results in predicted equilibrium wave heights comparable to wave heights found in the field.
\end{abstract}

\section{Introduction}

The bed of shallow shelf seas inhabits regular bed forms of various sizes. The largest of these bed forms are tidal sand waves and tidal sand banks, with wave lengths in the order of hundreds of meters to several kilometers, respectively. Sand banks are up to tens of meters in height. They are less dynamic than sand waves; the migration rate of sand banks is an order of magnitude smaller than the migration rate of sand waves (Dyer and Huntley, 1999). This makes them of less interest to offshore operations. Sand waves are observed in many tide-dominated sandy shallow shelf seas like the North Sea, Bisanseto Sea, Irish Sea, the shelves off the coast of Spain and Argentina, and in many straits and tidal inlets around the world (Van Santen et al., 2011). Typical migration rates for sand waves are in the order of $1-10 \mathrm{~m} /$ year, and can go up to tens of meters in areas with strong tidal currents (Knaapen, 2005). The height of sand waves is in the order of meters (typically 1-10 m), and the typical growth rate is in the order of $0.1 \mathrm{~m} /$ year. See Table 1 for an overview of sand wave characteristics. Examples of several sand wave fields at different locations in the North Sea are shown in Fig. 1.

The dimensions and migration of sand waves makes understanding their dynamic behaviour of particular importance to offshore activities. For instance, sand waves can affect the navigation depth as well as the stability of offshore platforms, pipelines and wind turbines, as pointed out by Németh et al. (2003). Knowledge about seabed dynamics could improve the design and increase the interval between surveys, so costs are reduced (Dorst et al., 2013). Therefore, coastal managers are in need for tools to formulate design criteria for offshore operations.

The formation of sand waves is explained as follows (Hulscher, 1996): sand waves are generated by small perturbations of the seabed that cause flow alterations. Considering continuity, the flow on the stoss side of the perturbation accelerates as a result of decreasing water depths, whereas on the lee side the flow decelerates as a result of increasing water depths. Because of the oscillating behaviour of the tide, this happens in both directions, causing residual circulation cells when looking at tide-averaged flow values. This results in a net transport of sediment towards the crest. Gravity causes transport from crest to trough, and acts as opposing factor. It is the balance between these two processes that determines the preferred wave length.

Various modelling studies have increased our understanding of sand wave dynamics, where a clear distinction can be made between linear and non-linear models. Linear stability models are used to predict the initial stages of formation of small-amplitude sand waves. The model approach introduced by Hulscher (1996) was later extended by Gerkema (2000); Komarova and Hulscher (2000); Besio et al. (2003). Tidal

\footnotetext{
* Corresponding author. Water Engineering and Management, University of Twente, Enschede, The Netherlands.

E-mail address: wietsevangerwen@gmail.com (W. van Gerwen).
} 
Table 1

Tidal sand wave characteristics from field measurements.

\begin{tabular}{|c|c|c|c|c|c|}
\hline \multirow[t]{2}{*}{ Source } & \multirow[t]{2}{*}{ Location } & \multirow{2}{*}{$\begin{array}{l}\text { Wave } \\
\text { length }\end{array}$} & \multirow{2}{*}{$\begin{array}{l}\text { Wave } \\
\text { height } \\
{[\mathrm{m}]}\end{array}$} & \multirow{2}{*}{$\begin{array}{l}\begin{array}{l}\text { Growth } \\
\text { rate }\end{array} \\
\text { [m/year }]\end{array}$} & \multirow{2}{*}{$\begin{array}{l}\begin{array}{l}\text { Migration } \\
\text { rate }\end{array} \\
\text { [m/year }]\end{array}$} \\
\hline & & & & & \\
\hline $\begin{array}{l}\text { McCave } \\
\text { (1971) }\end{array}$ & North Sea & $200-500$ & $2-7$ & - & - \\
\hline $\begin{array}{l}\text { Besio et al. } \\
\text { (2004) }\end{array}$ & North Sea & $120-500$ & $2-10$ & - & $1-8$ \\
\hline $\begin{array}{l}\text { Németh et al. } \\
\text { (2007) }\end{array}$ & $\begin{array}{l}\text { Gulf of } \\
\text { Cadiz }\end{array}$ & $150-300$ & $2-4$ & - & - \\
\hline $\begin{array}{l}\text { Cherlet et al. } \\
\text { (2007) }\end{array}$ & North Sea & $240-860$ & $2-6$ & - & - \\
\hline $\begin{array}{l}\text { Van Santen } \\
\text { (2009) }\end{array}$ & North Sea & $150-800$ & $1-9$ & - & - \\
\hline $\begin{array}{l}\text { Dorst et al. } \\
\text { (2011) }\end{array}$ & North Sea & $400-700$ & - & - & $0-7$ \\
\hline $\begin{array}{l}\text { Van Dijk et al. } \\
\text { (2011) }\end{array}$ & North Sea & $100-800$ & $1-10$ & 0.16 & $0-40$ \\
\hline $\begin{array}{l}\text { Van Oyen } \\
\text { et al. } \\
\text { (2013) }\end{array}$ & North Sea & $100-760$ & $0.5-5$ & - & - \\
\hline
\end{tabular}

asymmetry was investigated by Németh et al. (2002); Besio et al. (2004) and a depth dependent eddy viscosity with a no-slip condition at the bed was introduced by Blondeaux and Vittori (2005a, b); Besio et al. (2006). Roos et al. (2007) and Van Oyen and Blondeaux (2009) looked into grain sorting and Borsje et al. (2009) investigated the effect of benthic species on the preferred sand wave length. These models predict the stability of small perturbations superimposed on a flat bed, looking at different wave lengths. The perturbations that show positive growth rates are unstable, whereas the perturbations that decay are stable. The perturbation with the largest positive growth rate is titled the fastest growing mode $\left(L_{F G M}\right)$. This mode is assumed to prevail due to the weak non-linearity of the system (Dodd et al., 2003). These modelling studies show fair agreement with field data on wave length, migration rate and crest orientation.

To reach an equilibrium height, sand wave growth needs to reduce in time, for which non-linear terms need to be introduced. This is done in non-linear models, which are an add-on to the linear models (e.g. Németh et al., 2006, 2007; Van den Berg et al., 2012). Calculations in these models are done on a domain with the length equal to the $L_{F G M}$, this is done to prevent the growth of very long sand waves that would otherwise fill the domain, which is physically incorrect (Van den Berg et al., 2012). With this restriction, these type of models can predict growth towards a stable equilibrium. Sterlini et al. (2009) found that a residual current decreased the height significantly. However, these equilibrium heights were still larger than field observations.

Recently, a numerical shallow water model (Delft3D) has been used to predict the initial stages of sand wave formation (Borsje et al., 2013, 2014). This model enables the investigation of sand wave growth without the restriction of a domain with the length of the fastest growing mode, because the growth of very long sand waves is suppressed. This is achieved by the combination of an advanced turbulence model and suspended load transport (Borsje et al., 2014).

Despite all these studies, so far no model was able to reconstruct realistic equilibrium heights for sand waves. Therefore, the aim of this paper is to uncover the physical processes influencing the growth and equilibrium height of sand wave fields. This is done by using the numerical shallow water model (Delft3D) as presented in Borsje et al. (2013), running it for long periods of time and adding complexity in transport processes (including suspended load transport) and hydrodynamics (including tidal asymmetry via imposing a residual current to the symmetrical tide).

Section 2 describes the model set-up. The modelled influence of suspended load sediment transport and residual current strength on the equilibrium height are then presented in section 3. The model set-up and results are discussed in section 4 , followed by the conclusions in section 5.

\section{Sand wave model description}

The growth of sand waves is modelled using the numerical shallow water model Delft3D (Lesser et al., 2004). Using this model, Borsje et al. (2013) modelled the initial stages of sand wave formation, which they later extended by including suspended load transport in Borsje et al. (2014). Here, we limit ourselves to a summarized model description and refer the interested reader to Borsje et al. $(2013,2014)$ for a more detailed model description. (a)

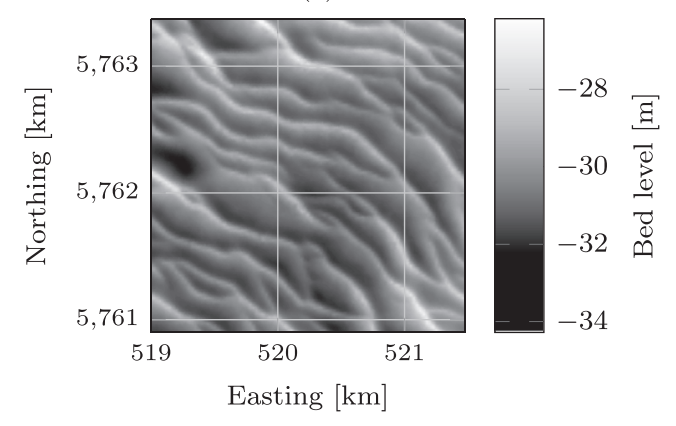

(c)

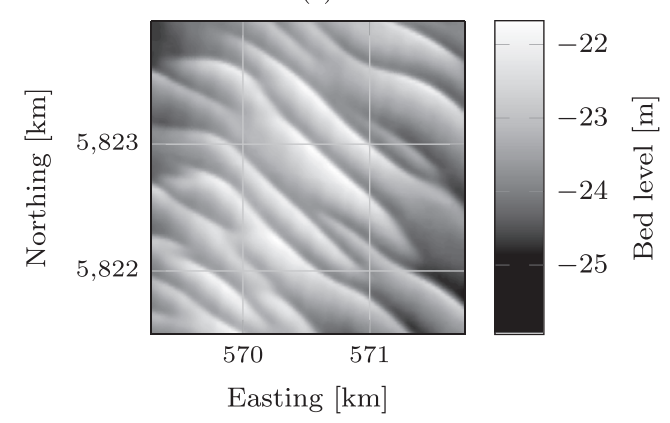

(b)

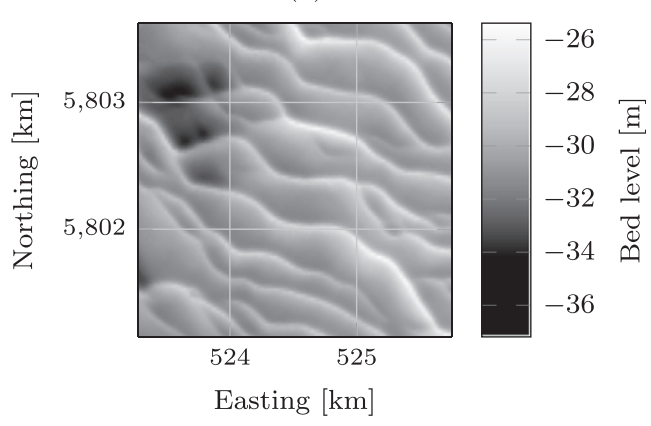

(d)

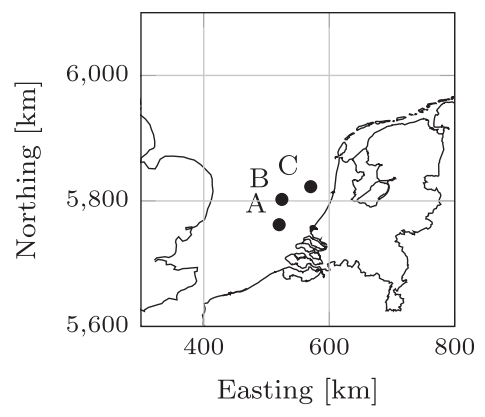

Fig. 1. Examples of sand wave fields (a, b, c) with its geographical location in the North Sea (d). 


\subsection{Hydrodynamics}

The system of equations consists of the Navier-Stokes equations, flowand sediment continuity equations and sediment transport equations. The vertical momentum equation is reduced to the hydrostatic pressure relation as vertical accelerations are assumed to be small compared to gravitational acceleration. The model equations are solved by applying $\sigma$-layering in the vertical orientation. In this study, the model is run in the two-dimensional vertical (2DV) mode, i.e. considering flow and variation in $x$ - and z-direction only, while assuming zero flow and uniformity in $y$ direction and ignoring Coriolis effects. At the length scales of sand waves, Coriolis effects have been shown to have a small influence (Hulscher, 1996).

In terms of the $\sigma$-coordinates, the $2 \mathrm{DV}$ hydrostatic shallow water equations are described by

$\frac{\partial u}{\partial t}+u \frac{\partial u}{\partial x}+\frac{\omega}{(H+\zeta)} \frac{\partial u}{\partial \sigma}=-\frac{1}{\rho_{w}} P_{u}+F_{u}+\frac{1}{(H+\zeta)^{2}} \frac{\partial}{\partial \sigma}\left(\nu_{T} \frac{\partial u}{\partial \sigma}\right)$

$\frac{\partial \omega}{\partial \sigma}=-\frac{\partial \zeta}{\partial t}-\frac{\partial[(H+\zeta) u]}{\partial x}$.

Here, $u$ is the horizontal velocity, $\omega$ the vertical velocity relative to the moving vertical $\sigma$-plane, $\rho_{w}$ the water density, $H$ the water depth below reference datum, $\zeta$ the free surface elevation, $P_{u}$ the hydrostatic pressure gradient and $F_{u}$ describes the horizontal exchange of momentum due to turbulent fluctuations. The vertical eddy viscosity $\nu_{T}$ is calculated by means of the $k-\varepsilon$ turbulence closure model in which both the turbulent energy $k$ and the dissipation $\varepsilon$ are computed (Rodi, 1980). The resulting vertical eddy viscosity $\nu_{T}$ is variable both in time and space. For details on the $k$ - $\varepsilon$ turbulence model formulations, see Burchard et al. (2008).

At the bed $(\sigma=-1)$, a quadratic friction law is applied and the vertical velocity $\omega$ is set to zero

$\tau_{b} \equiv \rho_{w} \frac{\nu_{T}}{(H+\zeta)} \frac{\partial u}{\partial \sigma}=\rho_{w} u_{*}\left|u_{*}\right|, \quad \omega=0$,

in which $\tau_{b}$ is the bed shear stress and $u_{*}$ is the shear velocity that relates the velocity gradient at the bed to the velocity $u$ in the lowest calculation grid point by assuming a logarithmic velocity profile.

At the free surface ( $\sigma=0$ ), a no-stress condition is applied and the vertical velocity $\omega$ is set to zero

$\rho_{w} \frac{\nu_{T}}{(H+\zeta)} \frac{\partial u}{\partial \sigma}=0, \quad \omega=0$.

\subsection{Sediment transport and bed evolution}

The bedload transport, $S_{b}$ is calculated by (Van Rijn et al., 2004)

$S_{b}=0.006 \alpha_{s} \rho_{s} w_{s} d_{50} M^{0.5} M_{e}^{0.7}$,

where $\alpha_{s}$ is the correction parameter for the slope effects (see below), $\rho_{s}$ the specific density of the sediment, $w_{s}$ the settling velocity of the sediment, and $d_{50}$ indicates the median sediment grain size. $M$ and $M_{e}$, respectively the sediment mobility number and excess sediment mobility number, are given by

$M=\frac{u_{r}^{2}}{\left(\rho_{s} / \rho_{w}-1\right) g d_{50}}, \quad M_{e}=\frac{\left(u_{r}-u_{c r}\right)^{2}}{\left(\rho_{s} / \rho_{w}-1\right) g d_{50}}$,

where $u_{r}$ is the magnitude of the equivalent depth-averaged velocity computed from the velocity in the bottom computational layer assuming a logarithmic velocity profile, $u_{c r}$ is the critical depth-averaged velocity for the initiation of motion of sediment based on the Shields curve. If $u_{r}<u_{c r}$, the bed load transport is set to zero.

Bed load transport is affected by bed level gradients, which causes sediment to move more difficult upslope than downslope. The correction parameter $\alpha_{s}$ for the slope effect is usually taken inversely proportional to the tangent of the angle of repose of sand $\varphi_{s}$ (Sekine and Parker, 1992)

$\alpha_{s}=\frac{1}{\tan \varphi_{s}}$.

The angle of repose of sand $\varphi_{s}$ is in the range between $15^{\circ}$ and $30^{\circ}$.

The suspended load transport $S_{s}$ is calculated by

$S_{s}=\int_{a}^{(H+\zeta)}\left(u c-\varepsilon_{s, z} \frac{\partial c}{\partial x}\right) d z$

where $a$ is the reference height (see below) and $c$ is the mass concentration, defined by

$\frac{\partial c}{\partial t}+\frac{\partial(c u)}{\partial x}+\frac{\partial\left(w-w_{s}\right) c}{\partial z}=\frac{\partial}{\partial x}\left(\varepsilon_{s, x} \frac{\partial c}{\partial x}\right)+\frac{\partial}{\partial z}\left(\varepsilon_{s, z} \frac{\partial c}{\partial z}\right)$,

where $\varepsilon_{s, x}$ and $\varepsilon_{s, z}$ are the sediment diffusivity coefficients in $x$ - and $z$ direction, respectively. Sediment transported below the reference height $a=0.01 H$ is regarded as bed load transport as it responds almost instantaneously to changing flow conditions (Van Rijn, 2007). Transport above this height is considered to be in suspension.

Finally, the bed evolution is governed by the sediment continuity equation (Exner equation), which reads

$\left(1-\varepsilon_{p}\right) \frac{\partial z_{b}}{\partial t}+\frac{\partial\left(S_{b}+S_{s}\right)}{\partial x}=0$,

in which $\varepsilon_{p}=0.4$ is the bed porosity, $S_{b}$ the bed load transport (eq:bedload), and $S_{s}$ the suspended load transport (eq:susload). eq:exner simply states that convergence (or divergence) of the total transport rate must be accompanied by a rise (or fall) of the bed profile.

Morphological changes occur on a much larger time-scale than the hydrodynamic changes. Therefore a morphological acceleration factor (MORFAC) is introduced. This allows for faster computations by multiplying the bed evolution after each time step by this factor (Ranasinghe et al., 2011).

The bottom roughness is described by the Chézy coefficient. Assuming hydraulically rough conditions, the White-Colebrook equation is used

$C=18 \log \left(12 H / k_{s}\right)$,

in which $H$ is the water depth and $k_{s}$ the roughness height. Following Cherlet et al. (2007), the roughness height can be evaluated by

$k_{s}=202 d R_{p}^{-0.369}$

in which the Reynolds number $R_{p}$ is evaluated by

$R_{p}=\frac{\sqrt{\left(\rho_{s} / \rho_{w}-1\right) g d^{3}}}{\nu}$,

with $\nu$ the kinematic viscosity of water.

\subsection{Model set-up}

The calculation grid has a variable resolution in both the $x$ - and $z$ direction (Fig. 2). In the center of the domain, the horizontal grid resolution is such that the distance between cells is $2 \mathrm{~m}$. Towards the lateral boundaries the resolution decreases up to $1500 \mathrm{~m}$ between cells. The total model domain is around $50 \mathrm{~km}$ in length (Fig. 2b). The vertical resolution is set to $60 \sigma$-layers, these layers have an increasing resolution towards the bed (Fig. 2c). A grid refinement study is conducted and illustrates that 60 vertical layers are sufficient to accurately describe the flow field. 
(a) Initial bed profile

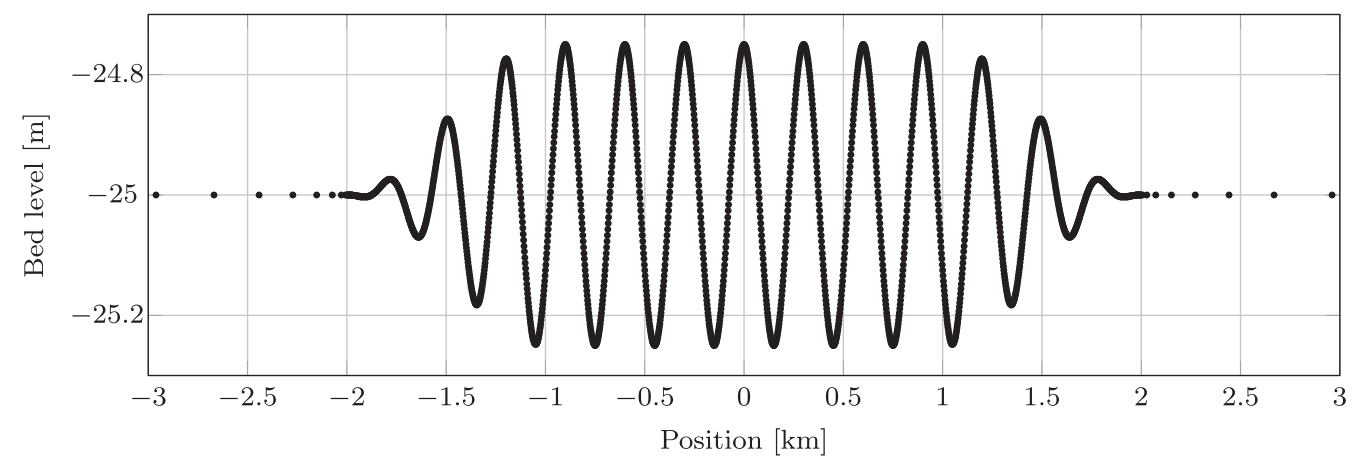

(b) Horizontal grid set-up

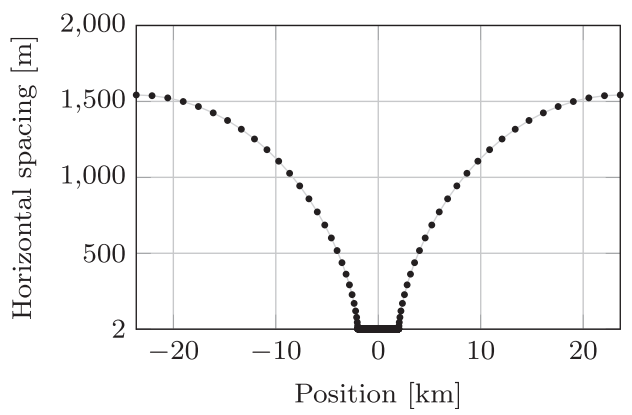

(c) Vertical grid set-up

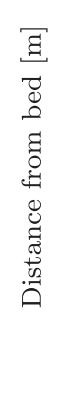

Fig. 2. The used calculation grid, with (a) an initial bed for a wave length of $300 \mathrm{~m}$, (b) the horizontal grid distribution for model runs with a symmetrical tide, using a fine grid in the center where the sand waves are calculated and a coarser grid towards the boundaries and (c) the distribution of the $\sigma$-layers over the water column, showing the distance from the bottom per layer for a mean water depth of $25 \mathrm{~m}$, resulting in $11 \sigma$-layers at the lower $1 \mathrm{~m}$ (e.g. at $x=-3 \mathrm{~km}$ in panel (a)). Note that the wave length of the initial bathymetry is equal to the fastest growing mode, which is determined by calculating the growth rate of individual wave lengths after one tidal cycle (Borsje et al., 2014). Consequently, the initial bathymetry is related to the environmental settings and varies per model simulation.
The center of the domain comprises sinusoidal sand waves with an amplitude of $1 \%$ of the mean water depth $(0.25 \mathrm{~m})$ as initial topography. This sand wave field is multiplied by an envelope function to ensure a gradual transition from the flat bed towards the sand wave field. The initial wave length is set to the fastest growing mode, determined by model simulations over a single tidal cycle, following Borsje et al. (2013). For long term calculations including residual currents, the $2 \mathrm{~m}$ grid resolution is extended into the direction of the migration.

Riemann boundary conditions are imposed at the lateral boundaries. This type of boundary condition allows the tidal waves to cross the open boundary without being reflected back into the computational domain. The hydrodynamic time step is set to $12 \mathrm{~s}$. To speed up the geomorphological changes, a MORFAC of 2000 is used. By using a MORFAC of 2000, the deposition and erosion fluxes are multiplied with a factor 2000 during each time step. Consequently, one tidal period corresponds to $12 \mathrm{~h}$ * $2000 \approx 2.7$ years of geomorphological changes. Smaller MORFAC values showed quantitatively the same results but required longer simulation times.

A tidal amplitude of $U_{S 2}=0.65 \mathrm{~m} / \mathrm{s}$ is used with a tidal frequency of $\sigma_{S 2}=1.45 \cdot 10^{-4} \mathrm{rad} \mathrm{s}^{-1}$. The hydrodynamic forcing can be extended with other tidal components, like the $U_{S 0}$ component. The bed slope correction parameter $\alpha_{b s}$ is set to 3, which corresponds to an angle of repose of sand of $19^{\circ}$. A Chézy roughness of $75 \mathrm{~m}^{1 / 2} / \mathrm{s}^{2}$ follows from these settings (eq. (11)). The chosen settings for the physical parameters represent typical conditions in which sand waves are observed (Borsje et al., 2014).

The model results are analysed on migration rate, wave height, wave length and the time scale to equilibrium. The migration rate is defined as the average horizontal disposition of the crest per year. The wave height is defined as the average vertical distance between a crest point and the two adjacent trough points. The wave length is defined as the horizontal distance between two subsequent trough points, and the time scale to equilibrium is defined as the time required to evolve from $10 \%$ to $90 \%$ of the equilibrium wave height (following Németh et al., 2004).

\section{Results}

The model was run for four different combinations of model settings, as presented in Table 2. For these field conditions, observed sand waves are typically up to $10 \mathrm{~m}$ (e.g. Besio et al., 2004; Cherlet et al., 2007).

Table 2

Overview of values and units of the model parameters and set-up for different tidal conditions.

\begin{tabular}{|c|c|c|c|c|c|c|}
\hline Description & Symbol & \multicolumn{4}{|c|}{ Value } & Unit \\
\hline $\begin{array}{l}\text { Tidal frequency of } \\
S_{2} \text {-tide }\end{array}$ & $\sigma_{S 2}$ & \multicolumn{4}{|c|}{$1.45 \cdot 10^{-4}$} & $\operatorname{rad~s}^{-1}$ \\
\hline Chézy roughness & $C$ & \multicolumn{4}{|l|}{75} & $\mathrm{~m}^{1 / 2} \mathrm{~s}^{-1}$ \\
\hline $\begin{array}{l}\text { Bed slope correction } \\
\text { parameter }\end{array}$ & $\alpha_{b s}$ & \multicolumn{4}{|l|}{3} & - \\
\hline $\begin{array}{l}\text { Median sediment } \\
\text { grain size }\end{array}$ & $d_{50}$ & \multicolumn{4}{|l|}{0.35} & $\mathrm{~mm}$ \\
\hline Mean water depth & $H_{0}$ & \multicolumn{4}{|l|}{25} & $\mathrm{~m}$ \\
\hline $\begin{array}{l}\text { Initial wave } \\
\text { amplitude }\end{array}$ & $A_{0}$ & \multicolumn{4}{|l|}{0.25} & $\mathrm{~m}$ \\
\hline Timestep & $d t$ & \multicolumn{4}{|l|}{12} & s \\
\hline $\begin{array}{l}\text { Morphological } \\
\text { acceleration factor }\end{array}$ & MORFAC & \multicolumn{4}{|l|}{2000} & - \\
\hline \multicolumn{2}{|l|}{ Model settings } & $\begin{array}{l}\text { Case } \\
\text { I }\end{array}$ & $\begin{array}{l}\text { Case } \\
\text { II }\end{array}$ & $\begin{array}{l}\text { Case } \\
\text { III }\end{array}$ & $\begin{array}{l}\text { Case } \\
\text { IV }\end{array}$ & \\
\hline $\begin{array}{l}\text { Amplitude of } \\
\text { horizontal } S_{0} \text { tidal } \\
\text { velocity }\end{array}$ & $U_{S 0}$ & 0 & 0 & 0.05 & 0.05 & $\mathrm{~m} \mathrm{~s}^{-1}$ \\
\hline $\begin{array}{l}\text { Amplitude of } \\
\text { horizontal } S_{2} \text { tidal } \\
\text { velocity }\end{array}$ & $U_{S 2}$ & 0.65 & 0.65 & 0.65 & 0.65 & $\mathrm{~m} \mathrm{~s}^{-1}$ \\
\hline Fastest growing mode & $L_{F G M}$ & 216 & 204 & 230 & 216 & $\mathrm{~m}$ \\
\hline $\begin{array}{l}\text { Suspended load } \\
\text { accounted for }\end{array}$ & - & No & Yes & No & Yes & - \\
\hline Required CPU time & - & 83 & 120 & 83 & 120 & $\mathrm{~h}$ \\
\hline
\end{tabular}




\subsection{Suspended load transport and tidal asymmetry}

We first analyse with a reference model set-up (Case I) using a symmetrical tide, where only bed load sediment transport is considered. The resulting growth curve is presented in Fig. 3. Towards the end of the simulation, the wave height is still increasing slightly, with about $5 \mathrm{~cm}$ per 30 years. After 150 morphological years the wave height is $9.6 \mathrm{~m}$, the time scale for this height is 77 years and the sand waves show no migration.

Case II includes suspended sediment transport, which results in a slightly smaller $L_{F G M}$ of $204 \mathrm{~m}$. Equilibrium is found at a wave height of $8.6 \mathrm{~m}$ in a time scale of 49 years and the sand waves show no migration.

Next, Case III considers a case with only bed load transport, using a hydrodynamic forcing consisting of a symmetrical tide and a residual current of $0.05 \mathrm{~m} / \mathrm{s}$. Similar to Case I, the wave height is not fully stable at the end of the calculation. After 150 morphological years the wave height is $8.7 \mathrm{~m}$, the time-scale for this height is 77 years and the migration rate is $3.2 \mathrm{~m} /$ year. The residual current causes sand wave asymmetry and migration. A residual current and suspended load transport both result in a reduction of the final sand wave height (Fig. 3).

Case IV considers suspended load transport and a residual current in the tidal forcing. Here, equilibrium is reached at a wave height of $7.6 \mathrm{~m}$ in a time scale of 58 years and with a migration rate of $5.4 \mathrm{~m} /$ year at the end of the simulation. The migration rate is significantly larger with the inclusion of suspended load transport.

The bed evolution of Case II and Case IV is visualised in Fig. 4, where the residual current in Case IV is imposed on the left boundary, flowing to the right. In this case, the sand waves become asymmetrical with smaller slopes on the stoss side than the lee side of the residual current direction. Additionally, the imposed $L_{F G M}$ remains constant over the modelling period. The asterisk and dot represent the tracking of a single crest and trough over time, respectively. The migration of the sand wave is clearly visible, the crest has moved $390 \mathrm{~m}$ in the direction of the residual current after 75 years (Fig. 4b). For the symmetrical tide the maximum flow velocity near the bed is $0.76 \mathrm{~m} / \mathrm{s}$ at the crest and $0.53 \mathrm{~m} / \mathrm{s}$ at the trough. The flow velocity in the trough is not large enough for sediment transport to occur.

\subsection{Residual current strength}

Next, the influence of the residual current strength on the wave height for Case II is studied. An increasing residual current strength results in a larger $L_{F G M}$ due to the increasing importance of suspended sediment and larger flow velocities, for example the $L_{F G M}$ is $204 \mathrm{~m}$ for the symmetrical case (Case II) and $326 \mathrm{~m}$ with a residual current strength of $0.2 \mathrm{~m} / \mathrm{s}$. The effect on the equilibrium sand wave height is shown in Fig. 5, a decrease in wave height is found for larger values of the residual current. For smaller residual currents this effect is small, and for larger residual currents the effect also decreases. For North Sea conditions the residual current strength is not likely to exceed $0.2 \mathrm{~m} / \mathrm{s}$. Buijsman and Ridderinkhof (2007) found values of up to $0.15 \mathrm{~m} / \mathrm{s}$ in the field. However, residual currents vary in time and orientation throughout the year, due to wind stresses, pressure differences and tidal interactions. Here we model the residual current as a constant in order to understand its effect. The used conditions show a linear increase of the migration rate with an increasing residual current strength. Before equilibrium is reached, the migration rate is not constant in time because the sand waves are still changing in asymmetry. After equilibrium is reached, the migration rate is constant in time, the difference in migration is no larger than $20 \%$ between the initial and final migration. This is in line with the findings by Németh et al. (2007).

Using hydrodynamic conditions consisting of a residual current and a symmetrical tide increases the maximum tidal excursion during flood (positive horizontal direction) and decreases the maximum tidal excursion during ebb.

Although this does affect the outcomes, it cannot be compared to an increase in flow velocities, as also indicated by Sterlini et al. (2009). This is tested by reducing the amplitude of the symmetrical tide such that the maximum flow velocity for the asymmetrical case equals the original symmetrical tide $\left(U_{S 0}=0.05 \mathrm{~m} / \mathrm{s}, U_{S 2}=0.60 \mathrm{~m} / \mathrm{s}\right)$. This causes a further reduction in wave height. Decreasing the flow velocity for a symmetrical case also decreases the wave height, but to a lesser extend (not shown here).

\subsection{Physical explanation}

As shown by Hulscher (1996), sand wave growth can be explained by the presence of tide-averaged circulation cells. For a symmetrical tide this circulation cell results in a net convergence of sediment towards the crest, counteracted by the slope effect. The tide-averaged flow velocity vectors are shown in Fig. 7(a). The circulation cells are clearly visible for the symmetrical case with suspended sediment (Case II). The upper figure shows the circulation cells during the growth of the bed form, while the lower figure shows the circulation cells for the equilibrium bed. Although the velocities are larger for this case, the steeper slopes have caused a balance in the driving and opposing forces.

The presence of suspended sediment transport has a dampening effect on the growth of sand waves, as shown by Borsje et al. (2014). For the here used model settings, the inclusion of suspended sediment transport (Case II) hardly leads to a difference in the $L_{F G M}$. However, suspended sediment transport has a significant impact on the equilibrium sand wave height. By including suspended sediment transport, the total transport

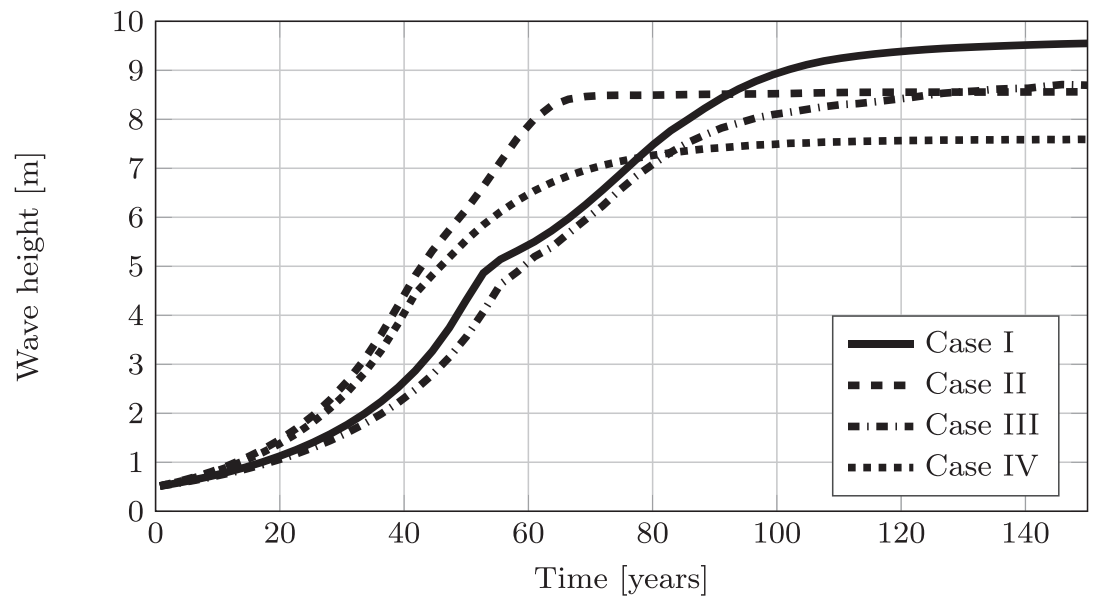

Fig. 3. Growth curve showing the wave height development in time for different combinations of model settings, where Case II and Case IV include suspended sediment transport on top of bed load transport. Case III and Case IV include an asymmetrical tide as opposed to the symmetrical tide in Case I and Case II. 
(a) Bed evolution of Case II

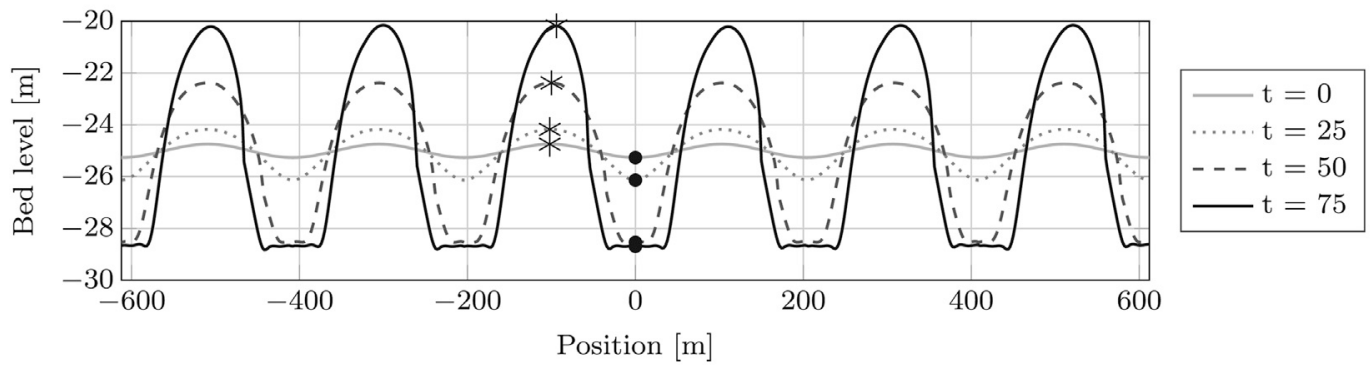

(b) Bed evolution of Case IV

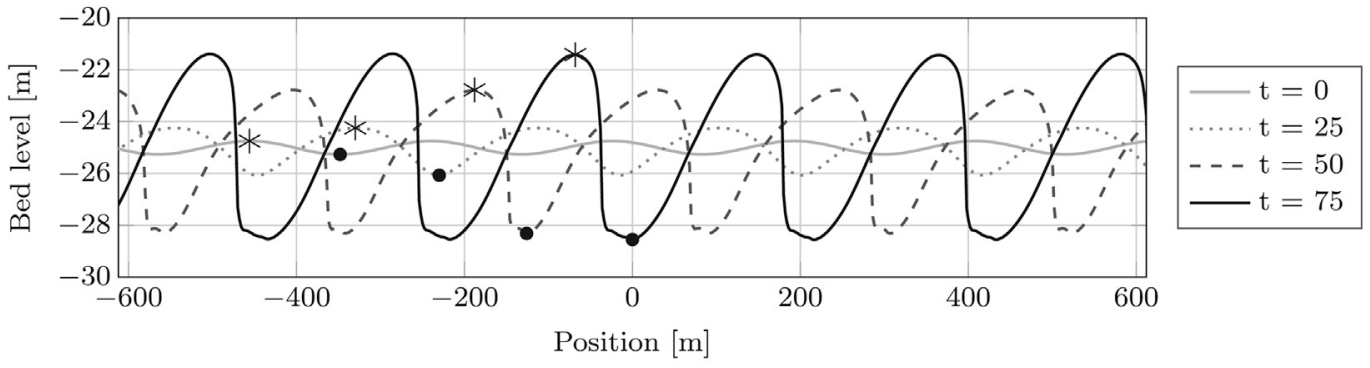

(c) Crest and trough development Case II

(d) Crest and trough development Case IV
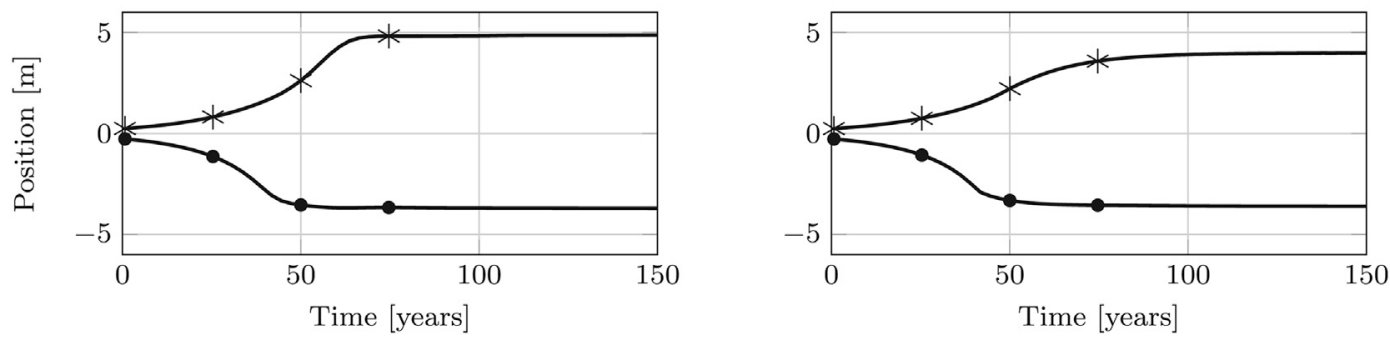

Fig. 4. Bed evolution in time (years), of (a) a symmetrical (Case II) and (b) an asymmetrical case (Case IV), both including suspended load transport. The growth of the crest and trough points relative to the mean initial water depth is depicted for (c) Case II and (d) Case IV. In all figures the location of the crest and trough points is tracked with an asterisk and dot, respectively.

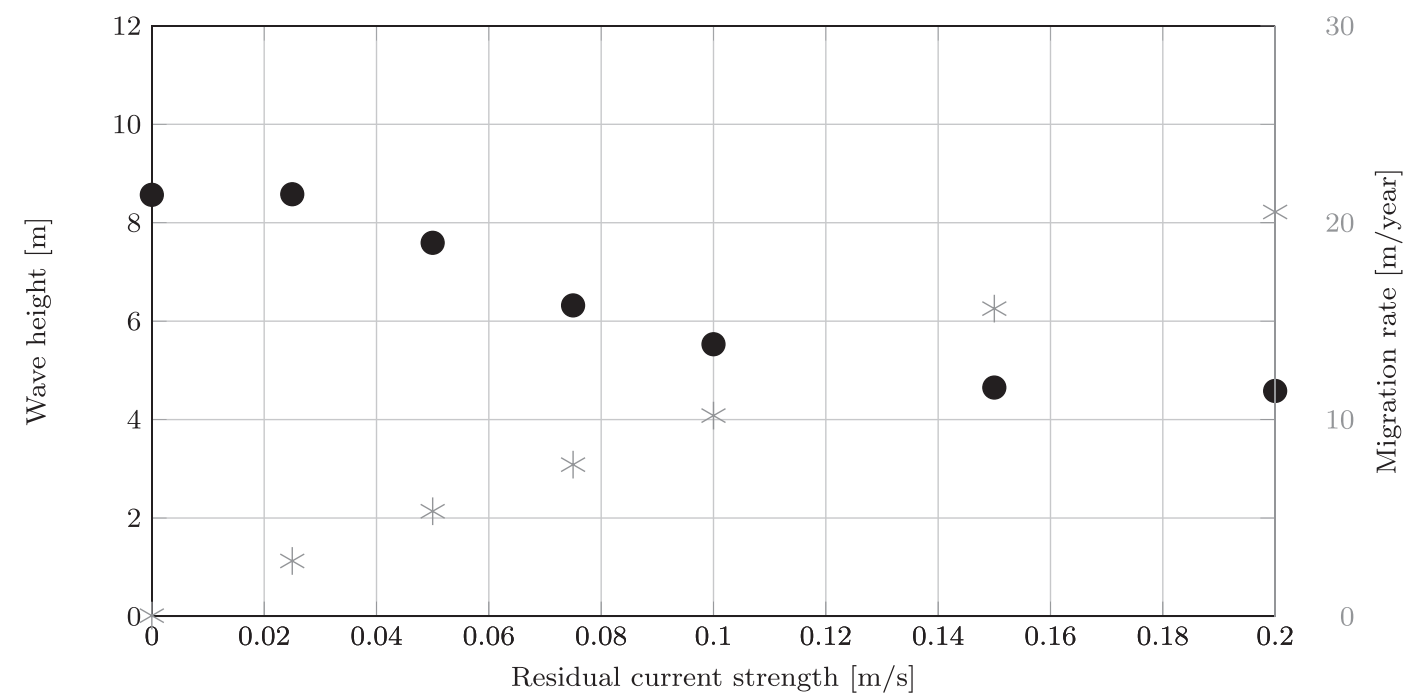

Fig. 5. Influence of the residual current strength on the equilibrium wave height (left, dots) and corresponding migration rate (right, asterisks). Note: the residual current strengths of $0 \mathrm{~m} / \mathrm{s}$ and $0.05 \mathrm{~m} / \mathrm{s}$ correspond to Case II and Case IV, respectively.

rate increases. For the grain size used in this model simulation $\left(d_{50}=0.35 \mathrm{~mm}\right)$, the suspended sediment is transported in the water column quite close to the bed and thereby behaves quite similar to bed load transport, resulting in higher initial growth rates, compared to the default simulation (Case I) (see Fig. 3). However, as soon as sand waves grow in amplitude, the suspended transport rate increases in magnitude 
and is at the same time transported through a larger portion of the water column. This leads to a dampening effect of the suspended sediment and consequently results in lower sand wave heights compared to the default model settings (Case I).

To further investigate the role of suspended sediment transport on the equilibrium height of sand waves, we decreased the grain size from $0.35 \mathrm{~mm}$ (Case II) to $0.30 \mathrm{~mm}$ and $0.25 \mathrm{~mm}$ (Fig. 6). As expected, the time to reach equilibrium is the shortest for the smallest grain size, since the transport rate is the largest for smaller grain sizes (section 2.2). Remarkably, the equilibrium heights are quite comparable for the three simulations. A decrease in grain size causes an increase in fastest growing mode (from $L_{F G M}=204 \mathrm{~m}$ for a grain size of $0.35 \mathrm{~mm}$, to $L_{F G M}=236 \mathrm{~m}$ and $L_{F G M}=256 \mathrm{~m}$ for a grain size of $0.30 \mathrm{~mm}$ and $0.25 \mathrm{~mm}$, respectively). In general, a longer fastest growing mode causes higher sand waves. However, at the same time a decrease in grain size causes a decrease in wave height due to the damping effect of suspended sediment transport. Consequently, a variation in grain size hardly influences the equilibrium wave height.

An explanation for the lower wave heights due to tidal asymmetry can be found in the hydrodynamics. A residual current causes a disturbance of the circulation cells such that convergence of sediment no longer occurs exactly at the crest. A tide-averaged flow in the direction of the residual current over the crest is observed. During the flood phase the velocities on the lee side of the sand wave are slightly lower than on the stoss side due to an increasing and decreasing water depth, respectively. During the ebb phase the opposite is observed, however, the tidal amplitude of the ebb phase is lower. Tide-averaged flow velocities on the stoss side are therefore larger than on the lee side. This residual flow causes a net transport in the direction of the residual current, which translates into migration and asymmetry of the bed form. Because this average flow is not uniform over the bed, convergence of sediment occurs at the points of smaller flow velocities, after the crest. This is shown in Fig. 7(b), where the lower figure is the equilibrium bed again and the upper figure the bed during growth. The contour plot shows that on the lee side and on the crest of the sand wave the flow velocities are smaller. This is more distinguished in the equilibrium (lower) plot as the slopes are steeper here. Furthermore, the threshold of motion for sediment transport is exceeded for a longer period of time during the flood phase. This all makes that sediment transport towards the sand wave crest is mostly coming from one side instead of two sides, as we see in the symmetrical case, thus resulting in lower sand waves.

In summary, for symmetrical tides an increase in tidal current velocity amplitude will result in longer and higher sand waves. For asymmetrical tides an increase in residual current strength will also lead to longer sand waves, however the sand waves will become lower.

\section{Discussion}

In this paper, we studied the growth of sand waves towards a stable equilibrium. Special attention was given to the influence of suspended load transport and tidal asymmetry on the growth and equilibrium height of sand waves.

The model predictions were very sensitive to the model parameters. Various model parameters were found to have an influence in the order of meters on the equilibrium wave height (e.g. the number of $\sigma$-layers, horizontal spacing $d x$ and slope parameter $\alpha_{b s}$, not shown here). Furthermore, the initially imposed bed influenced the model outcomes because most growth curves (for determining the $L_{F G M}$ ) showed only a small difference in maximum growth rate for a range of wave lengths. Because of this small difference, these wave lengths prevailed in the long term when they were imposed as initial bed for equilibrium calculations. Smaller values of the $L_{F G M}$ resulted in smaller wave heights than larger values of the $L_{F G M}$, all these model runs reached a stable equilibrium. To test the sensitivity of the wave length of the initial bathymetry to the final wave length, we imposed random perturbations as initial bathymetry and ran the model for the same model settings as Case II. The FGM found for Case II (204 m) fell within the range of wave lengths found from this selforganizational sand wave model (180-380 m).

The simulated front slope of the sand wave seems to be steep (Fig. 7). The maximum slope for Case IV was $36-53^{\circ}$, which only occurs over $4 \mathrm{~m}$ of the $76 \mathrm{~m}$ long sand wave slope. At all other points along the sand wave, the slopes were well below the critical value of $14^{\circ}$, which causes flow separation (Paarlberg et al., 2007).

To examine the influence of the resolution of the calculation grid on the model outcomes, a grid refinement study has been conducted. Compared to Borsje et al. $(2013,2014)$ this resulted in a finer grid with more $z$-layers and a smaller $d x$. A more refined grid was mainly required to accurately describe the long-term evolution towards equilibrium, while the short-term simulations (to determine the $L_{F G M}$ ) showed comparable results for both grid resolutions.

The introduction of a MORFAC is very convenient as it allows for long-term calculations, but it has a few limitations. As indicated by Ranasinghe et al. (2011), complex real-life situations may require significantly smaller MORFAC values. Studying the influence of a spring-neap tide is therefore not possible in the current set-up. Combining the $S_{2}$ and $M_{2}$ tidal components would result in a tidal forcing that varies on a much larger time scale. To achieve a similar accuracy, the MORFAC would need to be reduced accordingly. Furthermore, the total transport rates during one spring-neap cycle for (1) a spring-neap case and (2) a simplified case with only a $S_{2}$ component differ significantly. This has an effect on the formation and growth towards equilibrium of sand waves. Blondeaux and Vittori (2010) found a $30 \%$

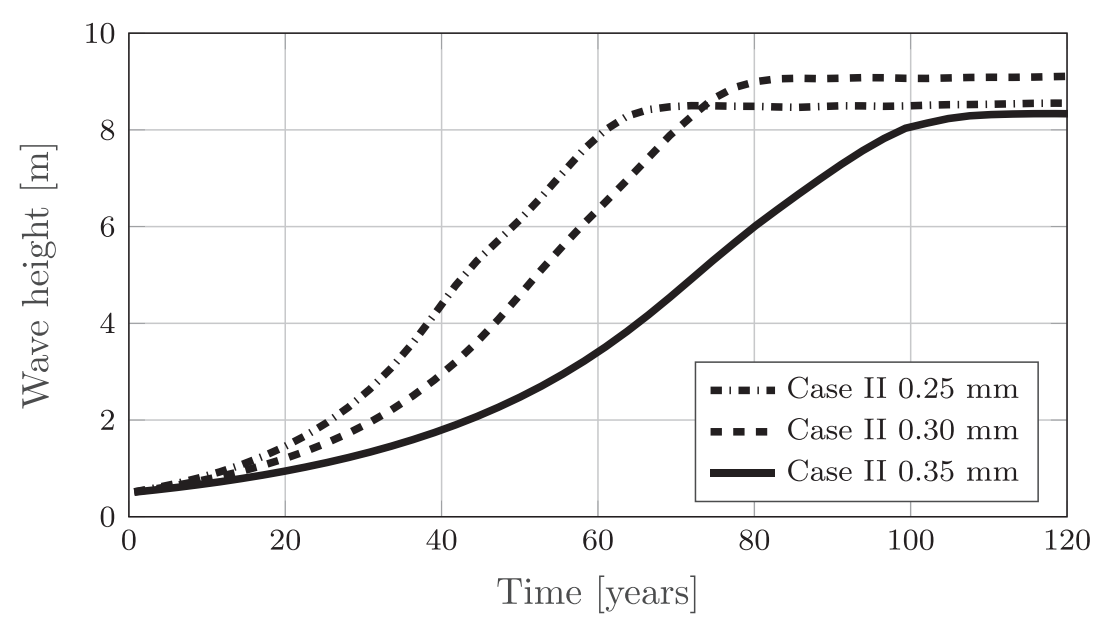

Fig. 6. Growth curve showing the wave height development in time for a variation in grain sizes. Note: a grain size of $0.35 \mathrm{~mm}$ resembles Case II. 
(a) Case II after 40 years
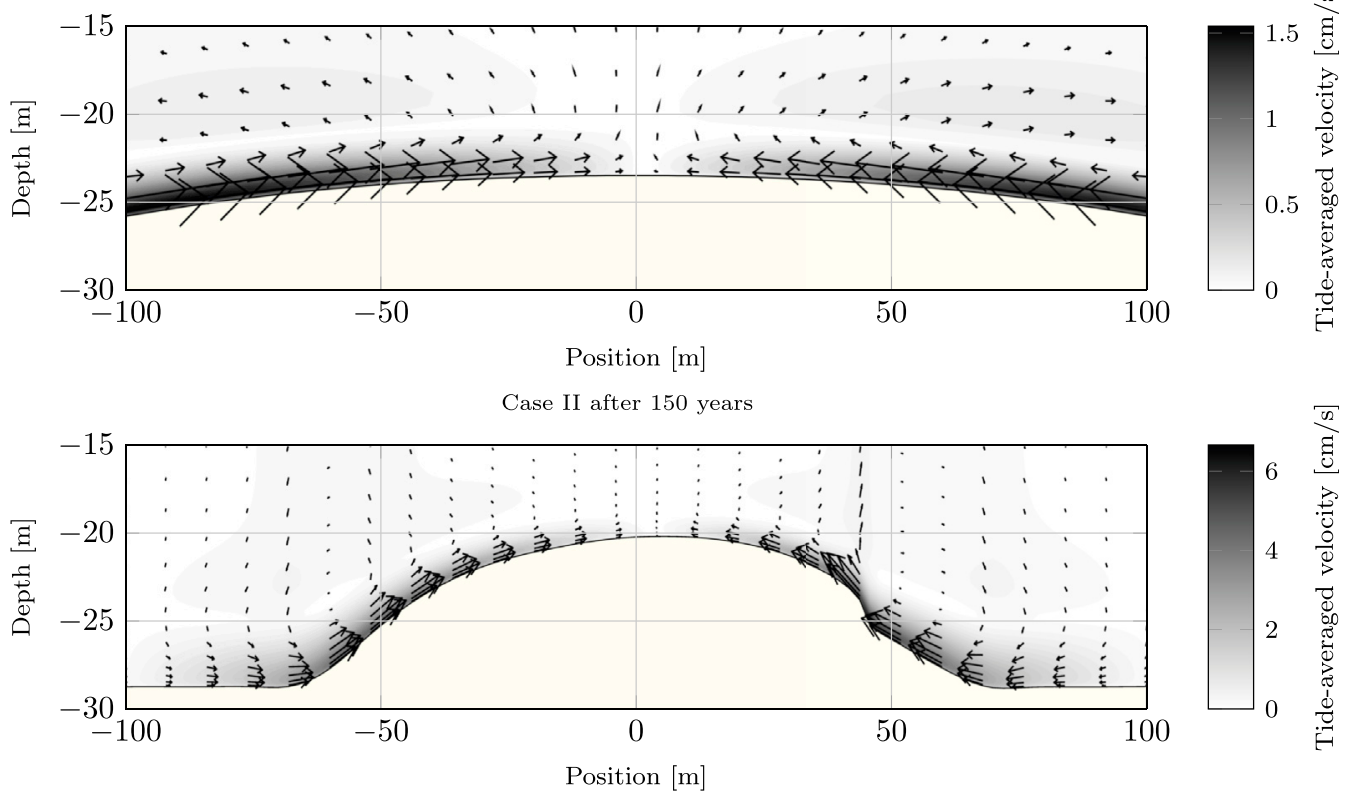

Fig. 7. Tide-averaged flow velocity amplitudes over sand waves for (a) a symmetrical case (Case II) and (b) an asymmetrical case (Case IV). (b) Case IV after 40 years

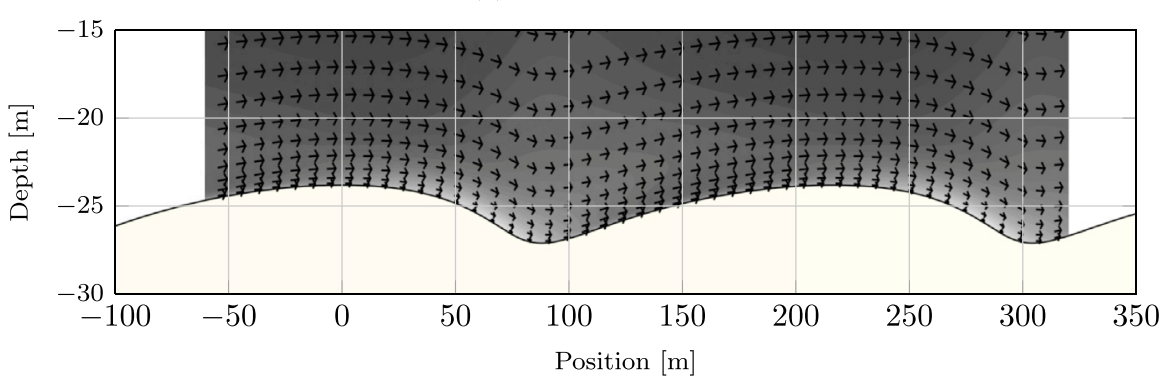

Case IV after 150 years

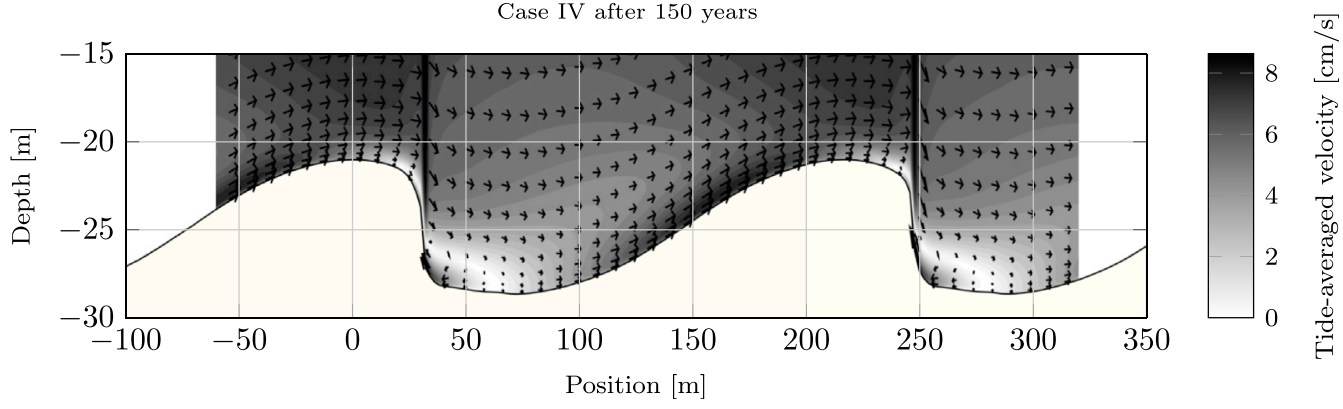

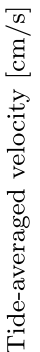

n
ह्व
0
0
0
0
0
0
0
000
00
0
0
0
0
0
0 difference in $L_{F G M}$ between the two cases. As also found by Sterlini et al. (2009), the currently used flow conditions predict the basic dimensions of the sand waves correctly. However, inclusion of other processes may result in sand waves of different shapes and sizes. Another process that could influence the equilibrium height of sand waves are wind waves and storms (Campmans et al., 2017b). Further processes that could be studied are grain sorting (as discussed by Roos et al., 2007; Van Oyen and Blondeaux, 2009) and the inclusion of biota (as discussed by Borsje et al., 2009). Both processes are currently being investigated in the framework of the SANDBOX programme (Damveld et al., 2015). Additionally, the effect of flow separation, which is not considered here, should be investigated further. Despite the exclusion of these additional non-linear processes, the simulated sand wave growth gives a good indication of the possible growth with equilibrium wave heights in the range of field observations (Table 1).
Although we were able to model sand waves from an initial perturbation to an equilibrium height, it requires large computational efforts (Table 2), which is a downside of the numerical shallow water model. The use of non-linear stability models (e.g. Van den Berg et al., 2012; Campmans et al., 2017a) may therefore be more appropriate when modelling the long-term qualitative evolution of sand waves. Such models would still require the inclusion of suspended load transport together with a turbulence closure model that allows for variation of the eddy viscosity both in time and space. The here presented model could then be used for detailed short-term predictions.

With the current model, a first indication of sand wave dynamics can be made, using more realistic processes than in previous studies, which results in sand wave characteristics in the same range as observed in the field. In particular, this model gives insight into how the dynamics are influenced by physical quantities. 


\section{Conclusions}

A numerical shallow water model (Delft3D) has been used to describe the growth of sand waves towards an equilibrium. The model was able to calculate a stable equilibrium from an initial disturbance on a large domain. For this, a careful treatment of the calculation grid was required, together with the inclusion of suspended load sediment transport.

The model results showed that suspended load transport and tidal asymmetry each had a significant dampening effect on the equilibrium wave height. When these processes were combined, the resulting wave height reduced even further. The growth of sand waves can be explained by the presence of tide-averaged circulation cells. Tidal asymmetry disturbs this mechanism such that convergence of sediment no longer occurs on top of the crest, but downstream of this point, which causes migration and asymmetry of the bed forms. The resulting equilibrium wave heights were in the same range as observed in the field.

\section{Acknowledgements}

The authors would like to acknowledge NWO-ALW, Royal Boskalis Westminster N.V. and Royal Netherlands Institute for Sea Research (NIOZ) for financing the SANDBOX programme and NWO-STW for financing the SMARTSEA programme. Parts of this work was carried out on the Dutch national e-infrastructure with the support of SURF Cooperative. Furthermore, the authors would like to thank ir. J.M. Damen for providing the data for Fig. 1 and ir. P.W.J.M. Willemsen for assisting in the model simulations.

\section{References}

Besio, G., Blondeaux, P., Brocchini, M., Vittori, G., 2004. On the modeling of sand wave migration. J. Geophys. Res. C Oceans 109, C04018.

Besio, G., Blondeaux, P., Frisina, P., 2003. A note on tidally generated sand waves. J. Fluid Mech. 485, 171-190.

Besio, G., Blondeaux, P., Vittori, G., 2006. On the formation of sand waves and sand banks. J. Fluid Mech. 557, 27.

Blondeaux, P., Vittori, G., 2005a. Flow and sediment transport induced by tide propagation: 1. The flat bottom case. J. Geophys. Res. C Oceans 110, 1-13.

Blondeaux, P., Vittori, G., 2005b. Flow and sediment transport induced by tide propagation: 2. The wavy bottom case. J. Geophys. Res. C Oceans 110, 1-11.

Blondeaux, P., Vittori, G., 2010. Formation of tidal sand waves: effects of the spring-neap cycle. J. Geophys. Res.Oceans 115.

Borsje, B.W., De Vries, M.B., Bouma, T.J., Besio, G., Hulscher, S.J.M.H., Herman, P.M.J., 2009. Modeling bio-geomorphological influences for offshore sandwaves. Continent. Shelf Res. 29, 1289-1301.

Borsje, B.W., Kranenburg, W.M., Roos, P.C., Hulscher, S.J.M.H., 2014. The role of suspended load transport in the occurrence of tidal sand waves. J. Geophys. Res. Earth Surf. 119, 701-716.

Borsje, B.W., Roos, P.C., Kranenburg, W.M., Hulscher, S.J.M.H., 2013. Modeling tidal sand wave formation in a numerical shallow water model: the role of turbulence formulation. Continent. Shelf Res. 60, 17-27.

Buijsman, M.C., Ridderinkhof, H., 2007. Long-term ferry-ADCP observations of tidal currents in the Marsdiep inlet. J. Sea Res. 57, 237-256.

Burchard, H., Craig, P.D., Gemmrich, J.R., van Haren, H., Mathieu, P.P., Meier, H.E.M., Smith, W.A.M.N., Prandke, H., Rippeth, T.P., Skyllingstad, E.D., Smyth, W.D., Welsh, D.J.S., Wijesekera, H.W., 2008. Observational and numerical modeling methods for quantifying coastal ocean turbulence and mixing. Prog. Oceanogr. 76, 399-442.

Campmans, G.H.P., Roos, P.C., De Vriend, H.J., Hulscher, S.J.M.H., 2017a. The influence of storms on finite amplitude sand wave dynamics: an idealized nonlinear model. In: 4th International Symposium of Shallow Flows. Eindhoven, The Netherlands, pp. 1-2.

Campmans, G.H.P., Roos, P.C., de Vriend, H.J., Hulscher, S.J.M.H., 2017b. Modeling the influence of storms on sand wave formation: a linear stability approach. Continent. Shelf Res. 137, 103-116.

Cherlet, J., Besio, G., Blondeaux, P., Van Lancker, V., Verfaillie, E., Vittori, G., 2007. Modeling sand wave characteristics on the Belgian continental shelf and in the calaisDover strait. J. Geophys. Res. 112, C06002.
Damveld, J.H., Borsje, B.W., Roos, P.C., Hulscher, S.J.M.H., 2015. Smart and sustainable design for offshore operations in a sandy seabed - the SANDBOX programme. In: MARID V.

Dodd, N., Blondeaux, P., Calvete, D., De Swart, H.E., Falqués, A., Hulscher, S.J.M.H., Rózynski, G., Vittori, G., 2003. Understanding coastal morphodynamics using stability methods. J. Coast. Res. 19, 849-865.

Dorst, L.L., Roos, P.C., Hulscher, S.J.M.H., 2011. Spatial differences in sand wave dynamics between the Amsterdam and the Rotterdam region in the Southern North Sea. Continent. Shelf Res. 31, 1096-1105.

Dorst, L.L., Roos, P.C., Hulscher, S.J.M.H., 2013. Improving a bathymetric resurvey policy with observed sea floor dynamics. J. Appl. Geodes. 7.

Dyer, K.R., Huntley, D.A., 1999. The origin, classification and modelling of sand banks and ridges. Continent. Shelf Res. 19, 1285-1330.

Gerkema, T., 2000. A linear stability analysis of tidally generated sand waves. J. Fluid Mech. 417, 303-322.

Hulscher, S.J.M.H., 1996. Tidal-induced large-scale regular bed form patterns in a threedimensional shallow water model. J. Geophys. Res. 101, 20727-20744.

Knaapen, M.A.F., 2005. Sandwave migration predictor based on shape information. J. Geophys. Res. Earth Surf. 110.

Komarova, N.L., Hulscher, S.J.M.H., 2000. Linear instability mechanisms for sand wave formation. J. Fluid Mech. 413, 219-246.

Lesser, G.R., Roelvink, J.A., van Kester, J.A.T.M., Stelling, G.S., 2004. Development and validation of a three-dimensional morphological model. Coastal Eng. 51, 883-915.

McCave, I.N., 1971. Sand waves in the North sea off the coast of Holland. Mar. Geol. 10, 199-225.

Németh, A.A., Hulscher, S.J.M.H., De Vriend, H.J., 2002. Modelling sand wave migration in shallow shelf seas. Continent. Shelf Res. 22, 2795-2806.

Németh, A.A., Hulscher, S.J.M.H., De Vriend, H.J., 2003. Offshore sand wave dynamics, engineering problems and future solutions. Pipeline Gas J. 67-69.

Németh, A.A., Hulscher, S.J.M.H., Van Damme, R.M.J., 2004. Modelling sand wave migration and height, comparing model results and data. In: Marine Sandwave and River Dune Dynamics, pp. 232-239.

Németh, A.A., Hulscher, S.J.M.H., Van Damme, R.M.J., 2006. Simulating offshore sand waves. Coastal Eng. 53, 265-275.

Németh, A.A., Hulscher, S.J.M.H., Van Damme, R.M.J., 2007. Modelling offshore sand wave evolution. Continent. Shelf Res. 27, 713-728.

Paarlberg, A.J., Dohmen-Janssen, C.M., Hulscher, S.J.M.H., Termes, P., 2007. A parameterization of flow separation over subaqueous dunes. Water Resour. Res. 43.

Ranasinghe, R., Swinkels, C., Luijendijk, A., Roelvink, D., Bosboom, J., Stive, M., Walstra, D., 2011. Morphodynamic upscaling with the MORFAC approach: dependencies and sensitivities. Coastal Eng. 58, 806-811.

Rodi, W., 1980. Turbulence Models and Their Application in Hydraulics - a State of the Art Review. University of Karlsruhe, Karlsruhe, Germany.

Roos, P.C., Hulscher, S.J.M.H., Van der Meer, F., Van Dijk, T.A.G.P., Wientjes, I.G.M., Van den Berg, J.H., 2007. Grain size sorting over offshore sandwaves : observations and modelling. In: Fifth IAHR Symp. On River, Coastal and Estuarine Morphodynamics. University of Twente, The Netherlands, pp. 649-656.

Sekine, M., Parker, G., 1992. Bed-load transport on transverse slope. J. Hydraul. Eng. 118, $513-535$.

Sterlini, F., Hulscher, S.J.M.H., Hanes, D.M., 2009. Simulating and understanding sand wave variation: a case study of the Golden Gate sand waves. J. Geophys. Res. 114, F02007.

Van den Berg, J.H., Sterlini, F., Hulscher, S.J.M.H., Van Damme, R.M.J., 2012. Non-linear process based modelling of offshore sand waves. Continent. Shelf Res. 37, 26-35.

Van Dijk, T.A.G.P., Van der Tak, C., De Boer, W.P., Kleuskens, M.H.P., Doornenbal, P.J., Noorlandt, R.P., Marges, V.C., 2011. The Scientific Validation of the Hydrographic Survey Policy of the Netherlands Hydrographic Office, Royal Netherlands Navy. Technical Report. Deltares.

Van Oyen, T., Blondeaux, P., 2009. Grain sorting effects on the formation of tidal sand waves. J. Fluid Mech. 629, 311.

Van Oyen, T., Blondeaux, P., Van den Eynde, D., 2013. Sediment sorting along tidal sand waves: a comparison between field observations and theoretical predictions. Continent. Shelf Res. 63, 23-33.

Van Rijn, L.C., 2007. Unified view of sediment transport by currents and waves. I: initiation of motion, bed roughness, and bed-load transport. J. Hydraul. Eng. 133, 649-667.

Van Rijn, L.C., Walstra, D.J.R., Ormondt, M.V., 2004. Description of TRANSPOR 2004 (TR2004) and Implementation in DELFT3D Online.

Van Santen, R.B., 2009. Tidal Sand Waves in the North Sea, Data Analysis and Modeling. Msc thesis (unpublished). University of Utrecht.

Van Santen, R.B., De Swart, H.E., Van Dijk, T.A.G.P., 2011. Sensitivity of tidal sand wavelength to environmental parameters: a combined data analysis and modelling approach. Continent. Shelf Res. 31, 966-978. 